\title{
Taking time to understand: articulating relationships between technologies and organizations
}

Article

Accepted Version

Whyte, J. (2010) Taking time to understand: articulating relationships between technologies and organizations.

Research in the Sociology of Organizations, 29. pp. 217-236. ISSN 0733-558X doi: https://doi.org/10.1108/S0733558X(2010)0000029016 Available at https://centaur.reading.ac.uk/17299/

It is advisable to refer to the publisher's version if you intend to cite from the work. See Guidance on citing.

To link to this article DOI: http://dx.doi.org/10.1108/S0733-

$558 \times(2010) 0000029016$

Publisher: Emerald Group Publishing Limited

All outputs in CentAUR are protected by Intellectual Property Rights law, including copyright law. Copyright and IPR is retained by the creators or other copyright holders. Terms and conditions for use of this material are defined in the End User Agreement.

www.reading.ac.uk/centaur 


\section{CentAUR}

Central Archive at the University of Reading

Reading's research outputs online 


\title{
TAKING TIME TO UNDERSTAND: ARTICULATING RELATIONSHIPS BETWEEN TECHNOLOGIES AND ORGANIZATIONS
}

Jennifer Whyte, University of Reading

Author version, final version published as:

Whyte, J. (2010) Taking time to understand: articulating relationships between technologies and organizations, Research in the Sociology of Organizations, Vol. 29, pp. 217-236.

Please cite the published version.

\begin{abstract}
Dynamic relationships between technologies and organizations are investigated through research on digital visualization technologies and their use in the construction sector. Theoretical work highlights mutual adaptation between technologies and organizations, but does not explain instances of sustained, sudden or increasing mal-adaptation. By focusing on the technological field, I draw attention to hierarchical structuring around inter-dependent levels of technology; technological priorities of diverse groups; power asymmetries; and disjunctures between contexts of development and use. For complex technologies, such as digital technologies, I argue these field-level features explain why organizations peripheral to the field may experience difficulty using emerging technology.
\end{abstract}




\section{INTRODUCTION}

Since Joan Woodward's (1980 [1965]) seminal work there has been considerable interest in exploring and explaining inter-relationships between technologies and organizations. However, in the trajectory of work inspired by Woodward, the approach of modern scholars differs from hers in important ways. Woodward's work is grounded in detailed empirical study of 1950s manufacturing firms in Essex, UK, and looks at inter-relationships between the technologies of production and management within the firm. Recent literature on organizations and institutions (e.g. Scott, 2001) shifts the focus to inter-relationships at the level of the field. This literature locates organizational practices in a broader institutional context, not only within the firm itself but also in practices that span firm boundaries (Orlikowski \& Barley, 2001).

This change in focus is an important step in a 'post Woodward' world. It allows us to acknowledge the nested nature of organizational structures within a society and provides a strong sociological basis for inquiry. Technologies become seen as potent means of making durable, transporting and replicating social structures; and the work of changing technologies takes on significant social and political dimensions (Garud, Jain, \& Kumaraswamy, 2002; Munir \& Phillips, 2005). Recent authors distinguish the technological field (Garud \& Karnøe, 2003; Granqvist, 2007) as a social structure that brings together the range of organizations interested in the development of a set of artifacts and techniques and use it to address questions about technological change. According to Granqvist, the technological field:

"refers to those organizations that, in aggregate, are engaged in development, use, regulation or exploitation of a technology or set of technologies, share a common meaning system and are in regular contact with one another." (Granqvist, 2007: 9)

The technological field is broader than the industry, including all the organizations that affect performance. The idea focuses attention on the social organization of technology development and use. It provides a context for understanding how firms 
are embedded, or engaged within a wider social structure; how some organizations may be more central and powerful than others; and how these power positions may be in flux.

In this paper, I draw on this concept of the 'technological field' to explore and contextualise inter-relationships between technologies and organizations. In the next section, I return to and provide a close reading of Orlikowski's classic description of these relationships, raising questions about the limits of mutual adaptation. The following section describes the setting and method of the empirical work. The findings highlight uses of digital visualization technologies within construction firms and discuss these in the context of the broader history of the technological field. Attention is drawn to disjunctures between development and use across the field and the implications of these disjunctures for sensemaking and decision-making within the user organizations. In conclusion, I highlight power asymmetries across the technological field, and the varying status and access of different firms as they face disjunctures between design and use.

\section{DEVELOPMENT AND USE OF TECHNOLOGIES}

The starting point for this study of relationships between technology and organization is the idea of mutual adaptation highlighted in the literatures (e.g. Leonard-Barton, 1988; Orlikowski, 1992). In her classic work on duality of technology, Orlikowski (1992) frames design and use as ongoing modes of action, thus reconciling previous descriptions of technology as either socially constructed in its design; or fixed in its use. She writes: 'Rather than positing design and use as disconnected moments or stages in a technology's lifecycle, the structuration model of technology posits artefacts as potentially modifiable throughout their existence' (Orlikowski, 1992: 408). Hence, the co-existence of design and use is important to her model of technology and organization.

Orlikowski (1992) argues that the traditional divisions of labor between the technology designers and the technology users blur in the case of computer-based artefacts. This allows her to emphasise the mutual constitution of technology and organization. However, revisiting the empirical case used in this classic paper, I 
notice disjunctures between the contexts of design and the contexts of use that are involved. As the functional consultants of Beta Corporation, the large multi-national software consulting firm from the North East of the USA, studied in 1987, adapt technology through their work, they are users and designers of slightly different technology. They are users of productivity tools, which were developed by their colleagues the technical consultants, as well as designers of customised applications for the firm's clients. They play a mediating role and are simultaneously both users and designers, but of different technologies.

Thus, development and use crosses firm boundaries. The functional consultants' working practices become inscribed into the practices of its client organizations through the technological solutions (customized applications) that they design. Orlikowski writes that 'Technology is built and used within certain social and historical circumstances and its form and function will bear the imprint of these conditions' (Orlikowski, 1992: 411). This raises questions about the circulation of technology from contexts of design into its contexts of use that are under-explored in the discussion of technology and organization. Orlikowski's focus in the paper is on how technologies become a more local 'mechanism for technical control, delimiting the ways [the functional] consultants [themselves] perceive and interact with their work' (Orlikowski, 1992: 417). However, tools developed in Beta Corporation not only contribute to Beta Corporation's structures of signification, but also contribute to those of their client organizations.

Uses of technologies depend also on the types of users and skills, but crucially here there is mutual adaptation across the boundaries of the organization. Though this wider adaptation is not commented on by Orlikowki, it is noted by one of her informants:

"In the front-end when we were designing with the screen and report design editors, we found we were leading clients on to accept the screens and reports in certain formats, because that's the way the design tool wants it done. So sometimes the client was forced to accept designs because of our technical environment." (reported speech of a functional consultant, from Orlikowski, 1992: 416). 
There is an interesting power relationship suggested by this consultant's explanation. The users within the client organization are forced to accept designs because of the technical environment at Beta Corporation. This deserves further theoretical attention as it implies disjunctures between contexts of technology design and contexts of use that are not fully theorized within this model of technology and organization.

As we will discuss further using the empirical data, the proliferation of mediating roles is a part of the history of information technology in general and digital visualization technologies in particular. The functional consultants that Orlikowski studied play a mediating role within the software consultant. Friedman (1994) notes how, from the 1960s onwards, the typical IT specialist comes to occupy a mediating position between bought-in computer systems and non-IT specialist users within the user organization and there is a massive increase in wider computer literacy (Friedman, 1994: 382). The changes to technologies through these mediating roles, and the questions about how developments across firm boundaries affect the potential for mutual adaptation and use within the firm lead to the research question: "How does the locus of development and use across a technological field pattern interrelationships between complex technologies and organizations?"

Before addressing this question through the empirical work, I want to clarify use of the terms technology and organization as scholarship has had to contend with widely varying definitions. Woodward's study takes a broad and inclusive definition of technology as the configuration of the firm's production system, but more recent work focuses on technology as artefact - focusing on particular material objects that are used to achieve tasks within an organization, or technology as a bundle of techniques - focusing on the capabilities and priorities that become embodied within such an artefact. Both approaches have merits, but here I use the latter definition of technology in order to articulate the various features (Griffith, 1999) of complex technologies and the priorities in the associated technological fields. I also treat the term 'organization' not as synonymous with 'firm' but as referring more broadly to purposeful social structures that involve co-ordination, both co-operative and antagonistic, in a routine manner. Organizations include the firms, government departments, voluntary associations and clubs across the technological field. 


\section{RESEARCH SETTING AND METHOD}

To illustrate and extend the above discussion, I consider the use of visualization technologies in the UK construction sector. I use the term 'digital visualization technologies' to indicate software applications that show 3D models and allow for real-time interaction. These include a range of simulation and prototyping technologies. Digital visualization technologies are important applications as they affect the way we see and comprehend the world, and ultimately, in the case of construction sector users, the way that it is built. On the personal computer, a range of interactive, real-time, 3D applications were beginning to be commercialized in the late 1990s, when I started researching the technological field in the UK, and the construction sector was seen as major potential market. A survey in the UK found a broad range of graphical systems were being used in work described as 'virtual reality':

The other striking thing is the broad range of software in use. Much of this cannot be classed by any stretch of the imagination as VR software, suggesting that many groups are still developing their own solutions to problems using underlying graphic systems. As in last year's report this may imply quite a large degree of duplication of effort. (Howard et al., 1995)

In the UK, virtual reality was being portrayed as an important new technology awaiting a ‘dominant design' (Swann \& Watts, 2000; Watts, Swann, \& Pandit, 1998). A UK government initiative, the Department of Trade and Industry (DTI)'s VR Awareness Programme (DTI, 2000), identified construction as one of five key sectors for VR use along with automotive, aerospace/defence, oil and gas, and major engineering contractors. The report states:

Of the five Key Sectors, the Construction industry professionals and trade organisations have been the most receptive to the DTI Awareness Programme, a promising indicator for future growth in this important market sector. (DTI, 2000). 
The UK made a substantial contribution to development of this technological field during the 1990s. It had related software and hardware industries, with virtual reality firms either headquartered (e.g. Division and Virtuality) or with regional offices in the UK. Research laboratories in the private sector, particularly those in recently privatised utilities, were conducting substantial VR research, for example British Telecoms (BT) was active and involved in standards development. Both the UK government and the European Union put substantial funding into research in this area. (By 2001, the EU had funded 105 projects that use 'virtual reality as a descriptor' and 24 of those were ongoing.) There were also active VR associations. The UK VR Special Interest Group was active 1993-1999; and it co-existed with regional groups such as the London VR Special Interest Group, which was active from 1996-2000, and the UK-based Virtual Reality Education Foundation (VeRGe), which was active 1992-1999.

These data were collected between 1997 and 2007, across a number of studies focused on aspects of the development and use of digital visualization technologies in this context. The approach here is to seek longitudinal and contextual understanding (Pettigrew, 1985) using these empirical data to develop and extend theories about conceptual relationships. I collected data using semi-structured interviews, participant observation and archival analysis, maintaining ongoing relationships with developers of visualization technologies and with their users in the construction sector. For example, I conducted interviews in 11 construction firms and 6 virtual reality suppliers in 2001. I also participated in the organizations within the technological field, for example attending most of the meetings of the London VR Special Interest Group from 1997 to 2000, where I often met with technology specialists from construction organizations. The London VR SIG had brought together people from high-end immersive VR labs and the games industry with researchers from particular industrial applications.

I conducted further interviews as part of cross-sectoral analysis of the use of digital visualization technologies conducted in 2005 and 2006, in some instances reinterviewing firms and individuals that I had first interviewed in 2001. This provided a context for hearing their reflections on the success and failure of previous implementation strategies. Building on previous work (Whyte, 2002, 2003) I use this 
data here to examine the dynamic inter-relationships between technologies and organizations in this setting.

In discussing the findings, the next section provides examples of uses of digital visualization technologies within construction firms and raises questions about why these firms are not able to mutually adapt technologies and organizations, rather facing a range of sustained, sudden or increasing mal-adaptation. The following section discusses the broader history of the technological field. It provides a broader context by describing the early developments within the field and the hierarchical structures within the field because of the complex nature of visualization technologies. Then the heterogeneous priorities of users across the field and the disjunctures between development and use are discussed.

\section{CONSTRUCTION SECTOR USERS}

The inter-relationships between technology and organization are difficult to understand by focusing solely on the construction sector user organization. The construction sector users that were the focus of my research were enthusiastic users of technologies that then became obsolete, either because they were based on standards that stopped being developed or because the firms that supplied them changed their strategic direction.

There was a significant research community developing solutions for the construction sector, with investment from the EU and UK research councils and a number of university-based VR laboratories for use in built environment applications. Many of these companies and others that I visited around this time, were working closely with universities on projects in this area. My conversations with IT specialists across the construction sector revealed a range of different strategies and priorities associated with using interactive real-time 3D software. Five examples are shown in Table 2.

Table 2: Five examples of discussions about interactive real-time 3D in different architectural, engineering and construction firms 


\begin{tabular}{|c|c|}
\hline Type of company & Visualization activities \\
\hline $\begin{array}{l}\text { Construction } \\
\text { Contractor A }\end{array}$ & $\begin{array}{l}\text { The firm has a 'positive drive towards a } 3 D \text { single data environment' they are } \\
\text { interested in 'how to control our projects using a system.' There are } 16 \text { people } \\
\text { that work in visualization in different parts of the company with } 13 \text { of those in } \\
\text { central office. They use both the major CAD packages, and my conversation } \\
\text { was with the senior CAD consultant and another CAD consultant }\end{array}$ \\
\hline Consultant Engineer & $\begin{array}{l}\text { This firm has a particular 'proof-of-concept' virtual reality tool that they had } \\
\text { developed following a number of highway projects on which it had used virtual } \\
\text { reality. The R\&D manager and IT manager demonstrated the tool's use on a } \\
\text { railway project. They felt that this would 'produce better and safer designs in a } \\
\text { shorter time.' Animations can be generated from the models to evaluate signal } \\
\text { visibility as well as checking the clearances to new platforms. }\end{array}$ \\
\hline Architect & $\begin{array}{l}\text { There are computer visualization specialists, and a CAD tool on every } \\
\text { designer's desk, with a large model shop with tools for making CAD generated } \\
\text { models. The Head of IT is skeptical about allowing the client to fly around a } \\
\text { model in real-time: 'Buildings don't get designed by pushing walls around'; } \\
\text { 'There is a naïve view that the client should be showed what they will } \\
\text { experience every day, however this is actually one aspect of a building.' }\end{array}$ \\
\hline $\begin{array}{l}\text { Construction } \\
\text { Contractor B }\end{array}$ & $\begin{array}{l}\text { The emphasis is on the single project model rather than the single building } \\
\text { model as they are interested in all the data that is not 3D as well as the } \\
\text { geometric information. The Head of Design and the Visualisation Manager } \\
\text { explained that: 'They are interested in virtual reality as a browser of the project } \\
\text { or object model' They are interested in selling a product and feel there may be } \\
\text { problems when VR becomes a contractual document. }\end{array}$ \\
\hline Project Manager & $\begin{array}{l}\text { In the UK there is a team of } 3 \text { visualization specialists, with another person } \\
\text { embedded in a major project. Here data for VR models comes from a variety of } \\
\text { CAD packages. They showed a } 5 \text { minute clip of a model that took } 200 \text { hours of } \\
\text { work to create. In the USA there is a team that started in } 1995 \text { and had peaked } \\
\text { at } 6 \text { people. Unusually for a firm in the construction sector this team uses } \\
\text { workstations. This team had recently become part of the firm's R\&D } \\
\text { department. }\end{array}$ \\
\hline
\end{tabular}

${ }^{*}$ In all of these companies the interviews were conducted in 2001, comments in quotations are taken from notes of the meetings.

Though most of this commercial use of interactive real-time 3D applications was at the 'proof of concept' stage, some firms had well developed visualization facilities and teams and significant investment in activities in this area. For example, the computer-aided design and visualization group of Construction Contractor B in Table 2 had 5-6 full time members of staff providing support to engineers on a wide range of projects. The Visualization Manager explained to me that the firm had a long history of using computer-aided design tools having obtained a main-frame computer in the early 1970s when he was a new member of staff. The office was full of personal computers and the team acted as a technology broker, learning about the newest and best technologies and introducing them to the wider firm. It had a particular focus on integrating data from multiple applications. 
As the technology champions within the firm (Construction Contractor B), this team mediates between the users within the firm and developers of technologies outside the firm. They also identified areas in which they believe that restructuring industrial practice around the process of developing models would lead to significant productivity improvements. For example, the team were convinced that using this software saved money by reducing the need to introduce costly or unsatisfactory 'work-arounds' at a late stage in the detailing process or on site. It made ensuring spatial compatibility between different engineering systems easier. However they expressed frustration that other members of the industry did not use these models. They felt that if the architect designed in 3D, then they would not have to be developing the model at such a late stage in the process.

What the strategies of these 5 firms have in common is the combination of development work in-house with externally sourced software; the interest in combining interactive real-time 3D applications with $\mathrm{CAD}$ and animation packages; and the strong interest in integration of data from a number of professional sources and software packages. All 5 firms are champions of real-time interactive 3D but the extent to which they use packages with these capabilities varies.

Yet the success of implementing these technologies was partial: the data suggests instances of sustained, sudden or increasing mal-adaptation as well as mutual adaptation. Construction Contractor A does not have a real-time interactive package, but has a strong emphasis on 3D modelling. The Consultant Engineer has developed its own 'proof-of-concept' tool using a 3D standard (VRML) which as we will see in the next section then stops being developed. Both of the members of staff interviewed had left in 2005. The Architect is relatively sceptical of the need for real-time interaction, though they have specialists that create highly-rendered realistic images they have less emphasis on interaction. Construction Contractor B is trialing a new software as discussed above, however the company is sold and this group is disbanded even before this software stops being developed. The Project Manager works with a CAD firm to develop visualizations for a later project. I will argue that this maladaptation as well as the adaptation of technology and organizations is best explained by theoretical work at the level of the technological field. 


\section{A HISTORY OF THE TECHNOLOGICAL FIELD}

In a technological field, organizational activity focuses on a shared set of technologies or technological visions (Granqvist, 2007: 9). Central players within the computer visualization field that emerged in the late $20^{\text {th }}$ century include the USA government which provided substantial research funding, the military, advanced manufacturing and entertainment firms that provided major user bases, the growing computer industry in the USA that spawned some of the related industries and firms; and SIGGRAPH a special interest group for people working with computer generated images. There is a shared vision of interactive, real-time, 3D visualization. Interaction means that there is a commitment to direct manipulation techniques. Real-time means that user input needs to be responded to seemingly instantly; 3D visualization means that a model needs to be shown. Common underlying graphic technologies became shared across a range of flight simulation, urban warfare simulation, film production and computer-aided design (CAD) solutions, with built environment applications such as real-time architectural walk-throughs discussed as potential applications of the emerging technology from the early days of the field.

\section{Users and developers through the early history of the field}

The technological field has its infancy in the 1950s, when the potential to achieve interactive, real-time, 3D visualizations on the computer is first understood. Real-time interaction is developed through military research from the 1940s onwards. The computer, 'Whirlwind', is a flight simulator developed as part of Project SAGE to create a computer-based air-defence system against long-range bombers. Though it was quite different to what we think of as a 'computer' today, with substantial physical mass, 10 tons weight and $150 \mathrm{~kW}$ power consumption (for only 1024 bytes $\mathrm{x}$ 2 banks of memory) it was the first computer designed to respond instantly to the user's input at the console. At this point in the history of the information technology field, users and developers were often the same people (Friedman, 1994: 376-377).

While computers such as Whirlwind were transforming computing from a 'batchprocess' operation to real-time interaction, it is through 1960s projects with manufacturing application that the potential for 3D visualization becomes realised (at 
least in the civilian context). The graphical system, 'Sketchpad', is developed at MIT to allow drawing of vector lines onto a computer screen with a light-pen. Other early examples of CAD packages include commercial packages such as DAC-1, used by General Motors in 1963. The USA government continues to fund most of this early research and is the single most sustained source of funding for visualization technologies (National Research Council 1999). A Special Interest Committee on Graphics was formed within the Association for Computing Machinery ACM in 1963 forming the basis for the later Special Interest Group (SIGGRAPH) in 1969.

The technological field expands and to some extent matures through the 1970s and 1980s. The first interactive architectural walkthrough system is developed at UNC Chapel Hill where researchers are using networks of high-end computers to get more processing power for complex 3D graphics; and developing techniques for the addition of colors, textures, lights and shading. During this period SIGGRAPH focused its efforts on standard development (Brown \& Cunningham, 2007). The development and use of visualization technologies begins to become more disaggregated across the field.

Then in the 1980s, basic real-time, interactive, 3D visualization begin to be possible on personal home computers as well as high-end systems. As the processing power, graphic capabilities and versatility of low end systems become sufficiently developed for widespread use, games on personal home computers become popular. For example, the game 'Elite' shows a basic line-based 3D universe on 8-bit machines. CAD packages are commercialised for use on personal computers, with Autodesk Inc starting in 1982 and Bentley Systems starting in 1985. Here there is a significant shift from dedicated machines with dedicated applications to commercial software packages and computers that can be used for multiple applications. It is in the late 1980s that the term 'virtual reality' is coined and that virtual reality software applications are first commercialised. Autodesk, for example, demonstrates a personal computer based virtual reality CAD package 'Cyberspace' at the major US graphics conference SIGGRAPH in 1989.

The idea of 'Virtual reality' becomes a focal point for development in the 1990s, although this focus is not uncontested. On 'high-end' hardware involving dedicated 
immersive facilities and UNIX-based Workstations, there are a range of virtual reality applications available. Many of these applications prioritise calculating and updating images to represent speed and movement rather than accurate geometry and scale within an environment. They are well suited to flight simulation, urban warfare and entertainment applications but not for built environment and manufacturing uses where geometric accuracy is crucial. At the same time as developments in immersive virtual reality, on 'low-end' hardware involving personal computers and screens, the games industry drove the development of a range of graphics cards. Open standards for a virtual reality modelling language (VRML) were developed for wider web-based applications. Although potential uses for designing buildings and cities continued to be part of the rhetoric of the field, construction industry users were not presented with clear technological options but rather had to make sense, interpreting the various dynamics of the field to decide about their own investments in technology.

\section{Hierarchical structure of the field}

By the 1990s, digital visualization technologies are complex technologies and the field is socially structured and organized around different aspects of these increasingly complex computer-based artefacts that need to be articulated. Hardware and operating systems are relatively standard and the computer visualization field as a whole uses these generic components. However, within the field, development work focuses on formats and standards; software applications and the add-on packages or macros that customise software applications to particular uses. This involves a hierarchical structuring of the field that patterns the power positions of different organizations around:

1. Hardware: Workstations and personal computers;

2. Operating systems: Unix on the workstation and MS Dos and then Windows on the personal computer;

3. Formats and standards: open standards (e.g. Open GL on Unix; VRML on Windows) and proprietary standards (e.g Performer on Unix; Direct 3D and Java 3D on Windows); 
4. Applications: these include a wide range of applications for virtual reality authoring, military simulation, gaming, film production etc; and

5. Add-on packages: include software that adds visualization capabilities onto other packages such as CAD and Geographic Information Systems (GIS).

The development of each item in the above list usually depends on the use of technology at the preceding level. Developments across the field are inter-connected and changes involved at the lower levels (smaller numbers in the above list) often cascade out into further changes involved at the higher levels (higher numbers in the list). Hence the pattern of interdependencies and changing power relations are interrelated with the articulated elements of the technology. A new hardware platform or operating system will require new activities in tailoring formats and standards, and rewritten applications and add-on packages. Though they are omitted from the above list, most digital visualization systems also involve some peripherals - from the mouse and light-pen, to haptic gloves, immersive displays and stereoscopic glasses. These were particularly important to many users of virtual reality and were sometimes also hardware or software dependent.

\section{DISJUNCTURES BETWEEN TECHNOLOGY DEVELOPMENT AND USE}

\section{Heterogeneous priorities across the field}

Generating high quality real-time 3D graphics continues to require substantial highend computing resources. Hence ongoing development within the technological field becomes structured around different sets of priorities: for real-time viewing; for geometric accuracy; and for high-quality graphics. In flight simulation and warfare simulation the priority is often given to real-time viewing and geometries are shown in less detail or with less accuracy where the computer does not have time to update a scene. In manufacturing and built environment applications the priority is often given to geometric accuracy and the view may slow where there are insufficient computational resources. In games the priority is often given to high-quality graphics, real-time interaction is also important, but geometric accuracy is less so and hence 
models are not fully detailed and may be one-sided or re-used within a scene to save computational power.

The priorities and interests of different sub-groups within the technological field are visible in interactions and strategic actions around formats and standards at the field level. In the mid-1990s, the Virtual Reality Modeling Language (VRML) was developed by independent programmers (based on Open Inventor) with the aim of developing networked virtual worlds. It became an open standard in 1997. The Workstation supplier Silicon Graphics championed this standard and employed an early advocate of virtual reality as a 'VR evangelist' from 1995-2001. However, Microsoft brought out Direct3D as a proprietary standard for Windows and Sun Microstation brought out Java 3D. Garud et al. (2002) trace the journey of the latter technology, but by the end of the 1990s it was the Microsoft proprietary standard that was most widely used by PC based games and hardware developers.

Associated with the diversity of technological priorities are disjunctures between development and use. These disjunctures have a geographic dimension. Despite an input of public money, the overall (UK-based) technological field became less rather than more coherent during the period studied. The disintegration of the self-organized researcher-led associations came at the same time as the government's VR awareness programme, which aimed to disseminate the use of technology into the industry. The committee of the London VR SIG, for example, agreed unanimously that the changes in the technology, markets and the group required a 'reframing', to broaden its outlook from conventional VR, be it immersive or desktop. In the email they circulated they suggest terms such as 'virtualised realities' and 'changing realities' to try to capture the wider feel, however no further meetings were then held and this group ceased to exist. The main disjunctures I focus on below, however, have a strong sectoral dimension.

\section{Disjunctures between Technology Developers and Users}

During the period in which fieldwork was conducted, construction sector users found themselves facing significant uncertainties as the customers and users for technologies that were in the process of disruptive and non cumulative change. There was a 
significant question around what hardware should be involved: whether advanced visualization should be a PC-based or Workstation based activity. High-end software firms were rewriting the software so that it would run on PCs as well as Workstations. This involved a transition from a UNIX based operating system to a Windows based system - a transition out of the high-end market in which users were themselves trained computer scientists comfortable setting up visualization through text based commands into a growing consumer market in which users expected more graphical modes of interactions in setting up as well as in viewing visualizations. The incumbent software providers found themselves ill-prepared for this wider market, in which they found themselves competing and also having to collaborate with a range of CAD, GIS and animation suppliers.

The high-end software suppliers were seeking to diversify away from military and flight-simulation and training applications and establish themselves as more generic visualization products. One of the major suppliers, interviewed in early 2001, was based in Los Angeles and had about fifteen years experience developing modelling and visualization software. Up until the late 1990s they had produced applications exclusively for SGI Workstations

\footnotetext{
"Now today we can take the same techniques that we do on the high end and deliver them on common PC hardware which is directly attributable to all the wonderful advances in processing speed but more importantly graphic card architecture and that is being driven ... by kids! The gaming industry, I mean it's wonderful."
}

Their firm had identified the built environment as a key area in which their software could provide benefit, but they were finding it a difficult market. They dedicated staff to developing customized urban simulations though they had little domain specific knowledge of the market in planning and construction. Their background was in military training applications, particularly flight simulation, and they found the needs of construction sector firms for data exchange with CAD problematic. The interviewee described their experience of the practices of construction users: 
" ... when they turn on the computer they are turning on their CAD program ... and CAD programs and virtual reality sometimes don't mix well, at least from our perspective they don't because we are into real-time visualization and that's a whole very focused discipline in 3D visualization."

During this period significant research effort was going into virtual reality in construction. At the same time, wary of the 'hype' surrounding the term 'virtual reality', high profile suppliers removed it from their literatures, with Multi-Gen, for example, re-branding themselves as suppliers of 'visual simulation.'

The enthusiastic use of technologies that then became obsolete by construction sector organizations is illustrated through a UK survey (Howard et al., 1995), in which the most widely used PC-based VR software package was used for fire simulation and for engineering simulation by the two construction sector firms that replied. Interest in the technology had brought together engineers and software developers from an unlikely mix of industries (including the porn industry) and in the late 1990s this package could be used to build stand-alone 3D applications and to author 3D webpages (it included VRML authoring capabilities). However, the developers of the software packages were themselves making decisions about which industry to be in as well as which technologies to use. I attended the rather heated user-group meeting in which the software firm announced its new strategy, which effectively abandoned their existing user base to follow a web-based e-commerce route (the firm now describes itself as a mobile games publisher of 3D wireless games).

\section{DISCUSSION: IMPLICATIONS FOR USER SENSEMAKING}

I have considered the dynamics across the various technological levels and the disjunctures between technology development and use in order to understand how the locus of development and use across a technological field pattern inter-relationships between complex technologies and organizations. The levels I discuss - hardware, operating systems, formats and standards, applications and add-on packages - are described in the practitioner literatures and are easily recognizable to the people I interviewed. They are used here to begin to articulate the hierarchical structure of the 
technological field and to articulate and disaggregate different contexts of development and contexts of use in order to theorise about their inter-relationships.

A challenge for organizations participating within a technological field is that it takes time to understand the dynamics across different levels. Individuals and organizations are constantly engaged in retroactive sensemaking to guide their future actions (Emirbayer \& Mische, 1998; Weick, 1995). Competing technological systems may exist together for some time in a relation of dialectical tension (Hughes, 1983) and it may be unclear to the majority of users which system will be durable. This is clearly a challenge to the construction user firms that were the focus of my investigations, and the sustained, sudden and increasing maladaptation that they experienced is only explainable in the context of these wider dynamics. Previous academic work has described the kind of disruptive innovation (Christensen, 2000) within the development industries that are involved. What has not been previously described is the difficulties this creates for users. More broadly, the dynamics across a technological field have implications for our understandings of relationships between technologies and organizations.

I have used Orlikowski's (1992) classic study on the mutual adaptation of technology and organization as a starting point for this investigation of relationships between technologies and organization. By introducing the concept of the technological field I shift attention to adaptations across organizational boundaries: to hierarchical structuring around inter-dependent levels of technology; technological priorities of diverse groups; power asymmetries; and disjunctures between contexts of development and use. The understanding that technology and knowledge circulates across such contexts is elaborated in a trajectory of theorising in the sociology of technology that has sensitised organizational theorists to such circulation across networks and contexts (e.g. Gherardi \& Nicolini, 2000). However, rather than focusing on the thing that circulates, in this paper I have sought to theorise about inter-relationships.

In this the idea of the technological field has been crucial. It allows the mediating roles to be made visible. This is particularly important as digital technologies have become more complex and their complexity structures relationships across a field, 
suggesting limits to the mutual adaptation of technology and organization. The close relationship between development and use described in Orlikowski (1992) may be seen as a special case, enjoyed by central actors with good connections. In her case, the functional consultants she studied were users of software developed in house by the technical consultants. However modern organizations are often users of software that is developed elsewhere: there are spatial and temporal disjunctures between development and use. The idea of a technological field provides a context for understanding the 'idiosyncratic strategies of individual organizations' (Hung and Whittington, 1997) as firms engage in strategic choices across pluralistic local contexts relating to technology and business.

A further implication of this study is the importance of taking time to understand. Just as it has taken me considerable time to analyse and interpret the data thus far (significantly more than I would have hoped), it takes organizations within the technological field significant time to make sense of their positions and to change their strategies. In seeking to understand the inter-relationships between complex technologies and organizations, a longitudinal and contextual approach to understanding the field seems to yield particular insight. The concept of the technological field used here is different from such concepts as 'technology trajectories' and 'dominant designs' in the economic literatures as these play little attention to the character of the users, the uses to which IT is put, and the labour market for IT specialists (Friedman, 1994). As technology becomes more complex, I argue that we need such broad sociological approaches that articulate and situate studies within the particular historical patterns of technology development and use.

\section{CONCLUSIONS}

The above data and discussion shows the limitations of a model of mutual constitution of technology and organization and its neglect of issues of competition and power. I find that what looks like mutual adaptation from the centre of a technological field may be mal-adaptation for those on the edge. Across a technological field, organizations vary in their status, access and ability to mutually adapt technology and organization, with less central and powerful organizations often experiencing 
sustained, sudden or increasing mal-adaptation. Thus in answering the question: "How does the locus of development and use pattern inter-relationships between complex technologies and organizations?" there are a number of disjunctures, which may be spatial and sectoral, but are in essence to do with different sets of priorities for further technological development. For example, there are disjunctures between construction industry users and the designers of virtual reality systems. Generic VR suppliers and resellers conceived of virtual reality as an entirely separate application creating a sense of presence but for construction industry users the access to engineering data and connectivity of CAD and VR were major issues.

This work has a number of implications. Most importantly, it implies that our theoretical understanding of the relationships between technology and organization cannot escape a consideration of the position of the organization within the technological field. It implies the need for longitudinal and contextual studies. The work also has practical implications for organizations that are looking to implement and use new technologies. Conceiving of technology strategies in relation to their position and power within a technological field, and the potential moves and outcomes that may be possible from that position will allow for more realistic strategising and help firms to make sense of mal-adaption. It also suggests a number of areas for further research.

Further research is needed to contextualise these findings within the wider academic literatures on information systems and organizations, to develop wider understandings of users, outside of those centrally located within technological fields, and to develop practical strategies for such firms. Despite substantial differences between my definitions and approach and that of Woodward, in seeking to develop theory that differentiates across organizations rather than providing a more singular theoretical approach I find myself returning to and re-enjoying a key contribution of her work.

\section{ACKNOWLEDGEMENTS}

I would like to thank Nelson Phillips, Graham Sewell, Libby Schweber and Nina Granqvist for helpful comments on earlier versions. 


\section{REFERENCES}

Brown, J. \& Cunningham, S. 2007. A history of ACM Siggraph. Communications of the ACM Archive, 50: 54-61.

Christensen, C. M. 2000. The innovator's dilemma. New York: Harper Business.

DTI. 2000. UK business potential for virtual reality, a market survey conducted by

Cydata Limited on behalf of the Department of Trade and Industry. London:

Department of Trade and Industry.

Emirbayer, M. \& Mische, A. 1998. What is agency? American Journal of Sociology, 103: 962-1023.

Friedman, A. L. 1994. The information technology field: Using fields and paradigms for analysing technological change. Human Relations, 47: 367-392.

Garud, R., Jain, S., \& Kumaraswamy, A. 2002. Institutional entrepreneurship in the sponsorship of common technological standards: The case of sun microsystems and java. Academy of Management Journal, 45: 196-214.

Garud, R. \& Karnøe, P. 2003. Bricolage versus breakthrough: Distributed and embedded agency in technology entrepreneurship. Research Policy 32: 277-300.

Gherardi, S. \& Nicolini, D. 2000. To transfer is to transform: The circulation of safety knowledge. Organization, 7: 329-348.

Granqvist, N. 2007. Nanotechnology and nanolabeling : Essays on the emergence of new technological fields. HSI, Helsinki.

Griffith, T. L. 1999. Technology features as triggers for sensemaking. Academy of Management Review, 24: 472-488.

Howard, T. L. J., Hubbold, R. J., Murta, A. D., \& West, A. J. 1995.1995 survey of virtual reality activity in the uk: The Advanced Interfaces Group, SIMA Report.

Hughes, T., P. 1983. Networks of power: Electrification in western society, 18801930. Baltimore and London: John Hopkins University Press.

Leonard-Barton, D. 1988. Implementation as mutual adaptation of technology and organization. Research Policy, 17: 251-267.

Munir, K. \& Phillips, N. 2005. The birth of the kodak moment: Institutional entrepreneurship and the adoption of new technologies. Organization Studies, 26: 1665-1687.

Orlikowski, W. J. 1992. The duality of technology: Rethinking the concept of technology in organizations. Organization Science, 3: 398-427.

Orlikowski, W. J. \& Barley, S. R. 2001. Technology and institutions: What can research on information technology and research on organizations learn from each other? MIS Quarterly, 25: 145-165.

Pettigrew, A. M. 1985. Contextualist research and the study of organizational change process. In E. Mumford \& R. Hirschheim \& G. Fitzgerald \& A. T. Wood-Harper (Eds.), Research methods in information systems: Proceedings of the IFIP WG 8.2 colloquium: 53-78. Amsterdam, New York, Oxford: New Holland.

Scott, R. W. 2001. Institutions and organizations. Thousand Oaks, CA: Sage Publications. 
Swann, G. M. P. \& Watts, T. P. 2000. Visualisation needs vision: The preparadigmatic character of virtual reality. In S. Woolgar (Ed.), Virtual society? technology, cyberbole, reality. Oxford: Oxford Univeristy Press.

Watts, T., Swann, G. M. P., \& Pandit, N. R. 1998. Virtual reality and innovation potential. Business Strategy Review, 9: 45-54.

Weick, K. E. 1995. Sensemaking in organizations. London: Sage Publications.

Whyte, J. K. 2002. Virtual reality and the built environment. Oxford: Architectural Press.

Whyte, J. K. 2003. Innovation and users: Virtual reality in the construction sector.

Construction Management and Economics (CM\&E), 21: 565 - 572.

Woodward, J. 1980 [1965]. Industrial organization: Theory and practice. Oxford: Oxford University Press. 